application, which must eventually grow out of their discovery, would likewise find their beginning in Germany, and in due course bear fruit there.

1 Naturwiss., 27, 11 (1939).

${ }^{2}$ Nature, 143, 470 (1939)

saturwiss., 27, 402 (1939).

4 Nature, 143, 239 (1939).

' $Z$. Phys. 119, 696 (1942).

- $Z$. Phys., 120, 450 (1943).

7 Z. Phys., 119568 (1942).

'Z. Phys., 122, 749 (1944).

- Z. Phys., 122, 769 (1944).

Publication of results for which no source is cited was prohibited during the War.

\section{A LONG-TERM PLAN FOR THE NILE BASIN}

$\mathrm{E}^{\mathrm{s}}$ GYPT, an agricultural country with practically no rainfall, is entirely dependent on the annual flooding of the Nile. Under natural conditions only that part of the country could be cultivated which was reached by the flood waters, and as the bulk of the population was generally little above the subsistence level, a poor flood meant widespread famine. The area of cultivation could only be extended by irrigation of land not reached by the natural flood; that is, by constructing dams to raise the level of the water, without interfering with the maximum level of the flood further downstream. The study of this possibility was begun about 1890 by Sir William Willcocks, as a result of which a relatively small dam was built at Aswan. This was completed in 1902, but was soon found to be inadequate; no other suitable site could be found at the time and the Aswan dam was heightened in 1912. Since 1920 the study of the Nile Basin has been assigned to the Physical Department of the Ministry of Public Works, Egypt, under the director-general, Dr. H. E. Hurst, who has gradually pushed investigations farther and farther upstream to the head-waters of the river in Lake Victoria in Uganda and Lake Tana in Abyssinia. From 1931 onwards a comprehensive series of reports has been issued under the title "The Nile Basin"; the present volume, by H. E. Hurst, R. P. Black and Y. M. Simaika, is the seventh of the series*.

The earlier proposals considered only how to make the best use of the flood water year by year. Storage from one year to another on the Nile itself presented very great difficulties, partly because of the immense volume of storage required to allow for a run of poor floods, and partly because of the enormous loss by evaporation in Egypt. Consequently, a poor flood still caused very great hardship; the situation was not so bad as it might have been because the Nile draws its water from a very large basin, and the fluctuations of rainfall were not in general similar over the whole area; but this advantage is largely offset by the losses in the extensive marshes of the Sudd. The Bahr el Jebel, which carries the whole of the discharge of Lake Albert, averaging 25 milliards (thousand millions) of cubic metres a year, flows through the flat Sudan plain, where it loses nearly half its water by evaporation and transpiration. Owing to this loss, the contribution of the White Nile to the main stream is relatively unimportant, and the bulk of the water supply of Egypt has to be met by the Blue Nile alone.

* The Nile Basin. Vol, 7: The Future Conservation of the Nile By Dr. H. E. Hurst, R. P. Black and Y. M. Simaika. (Ministry of Public Works, Egypt: Physical Department Paper No. 51.) Pp. $\mathbf{x i}+178+27$ plates. (Cairo: S.O.P. Press, 1946.) P.T. $125 ; 258$.
The population of Egypt is increasing rapidly, and the only way to guard against future famine is to accumulate a reserve of water so large that it can provide against the worst succession of bad years to be expected on any reasonable basis. This reserve must be in regions where evaporation is relatively small compared with that in Egypt, where the volume of water can be increased to a sufficient extent without greatly increasing the evaporating surface, and far enough apart for the variations from year to year. to be practically independent, so that runs of bad years would not be likely to coincide in all areas. The authors find that these requirements can be met by dams at Nimule below Lake Albert and at the outlet of Lake Tana, with possibly at a later stage a further reserve in Lake Victoria. The amounts of storage considered necessary, after allowing for the loss of some 40 per cent on the long journey to Aswan, are enormous ; they vary slightly according to different details in the plans but roughly amount to 140 milliards of cubic metres in Lake Albert and Lake Victoria together, with afterwards another 40 milliards, and anything up to 17 milliards in Lake Tana. Compared with these figures the capacity of the first Aswan dam, one milliard cubic metres, is indeed "a trifling amount". In order to reduce the losses in the passage of the Sudd, it will also be necessary either to dig a diversion canal or to embank the Bahr el Jebel. The scale of the problem is shown by the length of the proposed canal-about $300 \mathrm{~km}$. or nearly 200 miles: The ramifications are endless, ranging from consideration of the disturbance of dock and harbour facilities to the need to remove and rebuild churches. The cost would be very high, but against it must be set not only the livelihood of many more people in Egypt but also the prevention of flooding and the supply of hydro-electric power. These details are matters for a full engineering inquiry; but the authors have given a lead in what must be one of the most gigantic plans ever seriously put forward.

There is one detail which requires to be mentioned here. The authors repeatedly emphasize their idea of "Century storage", which briefly means that the reserve must be sufficient to deal with the greatest accumulated deficit to be expected in a hundred years. To obtain this figure, they examined a collection of about sixty long records of discharges, river-levels, rainfall, temperature and pressure, ranging from 10 up to as many as 200 years (with one river-level record of 400 years), and plotted the greatest accumulated departures from the mean values against the square root of the number of years. They write: "If we have $N$ observations of an element whose standard deviation is $\sigma$, then if $R$ is the maximum accumulated excess or deficit from the mean, on the average

$$
R=1.65 \sigma \sqrt{ } N
$$

...The form of this result is confirmed by theoretical investigations based on the theory of probability applied to the tossing of coins." Unfortunately, they do not give the theory, and the reviewer has not been able to find it anywhere in the literature of statistics; but the form of the expression seems to him to be incorrect. It is easily shown that in a series of values obeying the Gaussian distribution, the maximum possible accumulated departure is $0.4 \sigma N$, but the value of $0.4 N$ is less than 1.65 $\sqrt{ } N$ when $N$ is less than 17. Thus, for a series of less than seventeen years, the authors' expression 
gives an expected departure greater than the maximum possible. Detailed calculation would be difficult; but one would anticipate that the maximum deviation expected in $N$ years would bear a constant ratio to the maximum possible deviation, that is, $c \sigma N$, where $c$ is a constant less than $0 \cdot 4$. Now the accumulated departures in Plate XII only appear to fit in with the $\sqrt{ } N$ law because of one very aberrant figure for 400 years ; all the remaining points are fitted much more accurately by the curve given by $R / \sigma=0.2 \mathrm{~N}$. In a series of a hundred observations, this gives an accumulated departure 20 per cent greater than that estimated by the authors, and their "Century storage" reduces to 80 -year storage. This is not actually a very serious matter, as the uncertainties of some of the other figures are probably equally great, but it might be seized on by opponents.

So great a plan will require a long time to come to fruition-time which includes not only the building of the great dams and digging of channels, but also the many years required to build up the reserves of water. Everything depends ultimately on the rainfall of the upper parts of the Nile Basin; but the existing knowledge of the amount of rain and its long-term variation has many gaps, especially in Abyssinia, which must be filled by the setting up of new rain-gauges, and this is one of the first necessary steps. So far as one who is not an engineer can tell, Dr. Hurst and his colleagues have considered all that has to be done and the order of priority, and this should be of great help in the discussion of ways and means.

C. E. P. Breoks

\section{REDUCTION OF FIRE RISKS IN SHIPS}

$\mathrm{T}$ HE Admiralty Chemical Department, Portsmouth, has been busy of late with research into methods of reducing the fire risk on ships arising from paints and other materials used in them. An interim report recently made available reveals that the investigations have followed three lines ; namely, the development of fire-retardant paints for interior use particularly on metal surfaces, the fireproofing of textiles, and the fireproofing of plywood and soft timber.

Fire-Retardant Paints for Interior Use on Board Ship

Dried paint films on an organic base can be a powerful factor in transmitting fire, as experience during the War showed. Fire can be propagated from one compartment to another by means of the paint film on the bulkhead between them. Certain paint types when raised to a sufficiently high temperature on the side of the bulkhead remote from the actual conflagration-blister and form pockets of inflammable vapours. These vapours arise from the partial decomposition of the organic paint medium in the interior of the paint layer. The blisters finally burst, emitting jets of hot gas which ignite spontaneously and burn vigorously, transmitting the fire to any combustible material within reach.

The method used by the Admiralty for evaluating the fire-retardance of paints to be used in such circumstances is as follows. A steel plate, of standard thickness and 12 in. by 12 in. in area, is painted on one side with a primer/top-coat system in the normal manner, adequate time being allowed for drying. The plate is then heated in the vertical position on the unpainted side, with a gas ring supplied with air and gas under standardized pressure. The plate becomes red-hot in about 30 sec. Heating is continued for one minute, by which time combustion of the paint film has largely ceased. Any signs of flashing or flame-propagation are noted, together with any tendency for the red-hot film to detach itself from the plate. This test differentiated decisively between paints of good and bad fire-retardance. Large-scale trials upon painted plates, $6 \mathrm{ft}$. square, were carried out at the Admiralty Fire Testing Ground, Haslar, and the results established the validity of the laboratory test-procedure.

The tests showed that fire retardance was improved by reducing the proportion of medium so far as was consistent with durability and finish, and that titanium and antimony oxides were particularly effective as pigments in the top coat. The primer used was also important, an aluminium pigmented primer being adjudged to have better fire-retardant properties than a red-lead primer.

A specification for such paints has been prepared which prescribes the type of medium and the minimum proportions of titanium dioxide and antimony oxide to be used, and the correct pigment/medium volume ratio. Fire-resistance and other performance tests are included. Such paint is now in service use, but it has disadvantages, notably its matte surface, and work is at present in hand on the development of a finish of good gloss and adequate fire-retardance.

The experimental conclusion that antimony and titanium oxides are better than the other white pigments tested is interesting, in so far as their behaviour in the heated film must be essentially different; antimony oxide is comparatively volatile and easily reducible on heating with organic matter (such as would be present in the film), and titanium dioxide is particularly inert. Whereas it is admitted that antimony compounds are particularly valuable fire retardants in conjunction with textiles, opinion is divided on the fire-retardant value of antimony oxide in paint; thus an American Report (New York Paint and Varnish Production Club, 1943) on an investigation into fire-retardant paints for steel surfaces says that while in the particular tests reported antimony oxide was useful in preventing flashing in paints of low pigment volume, in paints of high pigment volume (as recommended by the Admiralty) it was the worst of the white pigments examined.

\section{An Inorganic Paint System}

Since a paint based on an organic medium can never be entirely incombustible however high the degree of pigmentation achieved, the investigation of paints based on inorganic media was a logical step in the Admiralty investigations. Among the materials examined was cementiferous paint originally developed to make use of the excellent anti-corrosive effect of zinc on steel surfaces and consisting essentially of a zine oxychloride cement containing a high loading of metallic zinc. Such paint showed great promise as a fire-retardant coating, but in its original form suffered from the following disadvantages : (1) It could not be stored in a ready for use form; it consists of two parts which had to be mixed immediately prior to application. (2) It was highly thixotropic and had poor flow properties. (3) Its colour was a dull grey which could not greatly be improved by the addition of white pigments.

It was found that the first defect could be overeome by the addition of an organic liquid as thinner. Thus 20 per cent by weight of industrial spirit 